\title{
Determinantes sociales de la trayectoria escolar de los universitarios chilenos. El caso de la Universidad Católica del Norte
}

\author{
Luis Miguel Rodrigo \\ Universidad Católica del Norte, Antofagasta, Chile. \\ Email: lrodrigo@ucn.cl \\ Aurora Sánchez \\ Universidad Católica del Norte, Antofagasta, Chile. \\ Email: asanchez@ucn.cl
}

\begin{abstract}
Resumen: Existe una carencia de trabajos sociológicos sobre la Educación Superior Chilena, especialmente de los enmarcados en las teorías de la reproducción social. Este artículo estudia, desde la teoría de Bourdieu, la trayectoria escolar de los estudiantes de la Universidad Católica del Norte (Chile). Se identifican cuatro momentos vitales de dicha trayectoria, I) la elección del tipo de colegio, II) los resultados en la prueba de acceso a la universidad, III) la elección del tipo de carrera y VI) el éxito en dicha carrera, que se analizan mediante árboles de clasificación y regresión, y coeficientes de localización, con información correspondiente al periodo 2002-2007. Los resultados muestran cómo el sistema escolar transforma el origen social de los estudiantes en atributos individuales, y cómo continúan sus efectos después de ingresar en la universidad.
\end{abstract} ción racional.

Palabras clave: trayectoria escolar, origen social, reproducción social, elec-

\section{Social determinants of school career in chilean college students. The case of the Catholic University of the North.}

\begin{abstract}
There is a lack of sociological work on Chilean higher education, especially works framed in theories of social reproduction. This article examines, from Bourdieu's theory, the school careers of students from the Catholic University of the North (Chile). Four vital moments of this trajectory are identified, i) the choice of school, II) the results in the entrance examination to college, III) the choice of career and VI) the success in it. These moments are analyzed using classification and regression trees, and coefficients of localization, with information for the period 2002-2007. The results show how the school system transforms the social origins of students in individual attributes, and how the effect of these attributes persist after entering college.
\end{abstract}

Keywords: school career, social origin, social reproduction, rational choice. 


\section{Determinantes sociais da trajetória escolar dos universitários chilenos. $O$ caso da Universidade Católica do Norte.}

Resumo: Existe uma carência de estudos sociológicos sobre Ensino Superior Chileno, especialmente daqueles enquadrados nas teorias da reprodução social. Este artigo analisa, a partir da teoria de Bourdieu, a trajetória escolar dos estudantes da Universidade Católica do Norte (Chile). Identificam-se quatro momentos vitais desta trajetória: I. A escolha do tipo de colégio; II. Os resultados no exame de admissão para a faculdade; III. A escolha da carreira e VI. O sucesso neste curso, os quais se analisam segundo árvores de classificação e regressão, e coeficientes de localização, com informações para o período de 2002-2007. Os resultados mostram como o sistema escolar transforma a origem social dos estudantes em atributos individuais, e como seus efeitos continuam depois de entrar na faculdade. racional.

Palavras-chave: trajetória escolar, origem social, reprodução social, escolha

$* * *$

\section{Introducción}

La equidad en el acceso a la Educación Superior y en la trayectoria escolar de los estudiantes son dimensiones importantes para analizar la evolución del sistema de Educación Superior en Chile y el rol que éste podría tener para alcanzar los niveles proyectados de desarrollo socioeconómico (Franco, León y Atria, 2007). Es también esta aspiración de alcanzar una mejora educativa la que destaca la OCDE (2009:11) en su informe de la Educación Superior en Chile.

Los determinantes del acceso a la Educación Superior han sido influidos de alguna manera por los cambios estructurales significativos ocurridos en la sociedad chilena. Estos cambios fueron el producto de la transición de un modelo económico protegido donde el Estado tenía un rol fundamental en la década de los setenta hasta un modelo económico de libre mercado con la globalización como eje central y con el sector privado liderando la mayoría de las iniciativas previamente dejadas en manos del Estado. En este sentido, la reforma educacional de 1980 creó una nueva estructura de administración y gobierno de las escuelas primarias y secundarias donde se produjo el traspaso de las escuelas desde el Ministerio de Educación, quien fijaba los planes y programas y atendía a cerca del 80\% de la matricula, a las municipalidades, que se hicieron cargo de la administración de los colegios. Este traspaso tuvo como propósito el descentralizar la administración de los colegios. Estos cambios, sin duda, afectaron la estructura y el acceso a la educación permitiendo la existencia de calidades dispares entre colegios según el modelo de financiamiento asociado (ver gráfico 1). 


\section{Grafico 1: Índice de estatus económico, social y cultural vs. Puntajes en PISA por tipo de colegio}

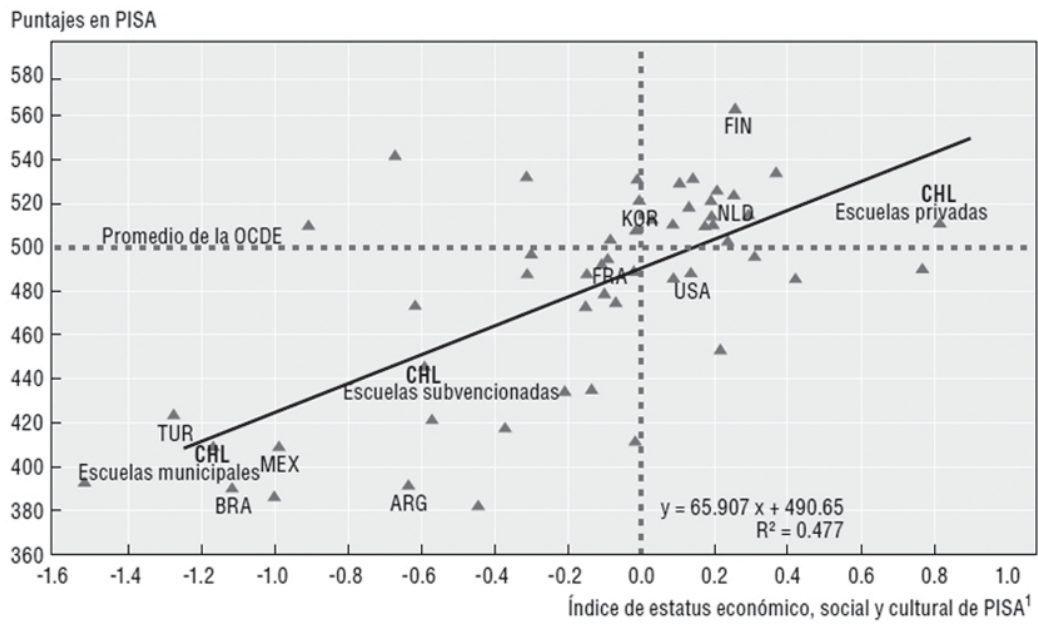

Fuente: OCDE (2010), Estudio económico de Chile 2010

Como podemos observar en el gráfico 1 existe una gran desigualdad social entre los estudiantes chilenos pertenecientes a las escuelas municipales, subvencionadas y privadas, además, esta desigualdad social se reproduce nítidamente en sus resultados escolares (Puntajes PISA).

Investigadores nacionales y organismos internacionales reconocen efectos positivos y negativos en el cambio del modelo de educación chileno. Entre los aspectos positivos, destaca el aumento significativo en la extensión de la Educación Superior (Navarro, 2002; García y Bellet, 2003; García, 2005; Castillo, 2007 y 2009; OCDE, 2009; Brunner, 2009A y 2009B; MINEDUC), de hecho, las matriculas en la Educación Superior casi se han triplicado desde 1990 (Zapata y Tejeda, 2008). Asimismo, el informe del Consejo asesor presidencial para la educación indica que la proporción de jóvenes de 18 a 24 años pertenecientes al I y II quintil que ingresaron a la Educación Superior se ha duplicado entre 1998 y el 2006. Este informe también destaca que cerca del 70\% de quienes asisten hoy a una institución de Educación Superior en Chile, son hijos de padres que nunca asistieron a ese nivel educacional (CAP, 2008).

Los efectos negativos del modelo se reflejan principalmente en la falta de equidad en el acceso a las instituciones de Educación Superior y en las trayectorias escolares de los estudiantes. Organismos internacionales como la OCDE han solicitado reformas tendientes a disminuir la desigualdad de acceso de los estudiantes pertenecientes a grupos de bajos ingre- 
sos (OCDE, 2009). Esta falta de equidad (tabla 1) puede observarse en la sub-representación en la matrícula universitaria de alumnos de colegios municipales y en la sobre-representación de los alumnos de colegios privados (MINEDUC).

\section{Tabla 1: Distribución de la matrícula de 4to medio por tipo de colegio año 2010 (porcentajes)}

\begin{tabular}{|l|l|l|l|l|l|}
\hline $\begin{array}{l}\text { Tipo } \\
\text { Institución }\end{array}$ & $\begin{array}{l}\text { Colegios } \\
\text { Municipales }\end{array}$ & $\begin{array}{l}\text { Colegios } \\
\text { Subvencionados }\end{array}$ & $\begin{array}{l}\text { Colegios } \\
\text { Privados }\end{array}$ & OTROS & TOTAL \\
\hline 4to Medio & $41 \%$ & $46 \%$ & $13 \%$ & $0 \%$ & $100 \%$ \\
\hline Universidades & $29 \%$ & $44 \%$ & $21 \%$ & $6 \%$ & $100 \%$ \\
\hline
\end{tabular}

Fuente: Elaboración propia a partir de datos del Consejo Nacional de Educación, Índices 2011

Otros investigadores nacionales han criticando las diferencias que aun existen en las probabilidades de acceso de los sectores menos privilegiados de la sociedad, sosteniendo que estas diferencias llegan a ser casi del 40\% (Castillo y Cabezas, 2010). Zapata y Tejeda (2008) reconocen la extensión de la matrícula universitaria, pero destacan la falta de equidad de este aumento y la alta segregación socioeconómica de la población por tipos de establecimientos escolares. Los autores también destacan las diferencias en el gasto en educación por estudiante, los amplios contrastes en el rendimiento e indicadores de logro según su condición socioeconómica y las importantes brechas de cobertura en Educación Superior de los quintiles más pobres (CAP, 2008).

La relación entre las propiedades sociales de los estudiantes y su trayectoria escolar ha sido objeto tradicional de investigación en sociología de la educación (Bourdieu y Passeron, 1970/ 2001). La evidencia empírica muestra una fuerte relación entre la clase social de los estudiantes y su trayectoria escolar, tanto para los países "desarrollados" como para los países “en vías de desarrollo” (Martínez García, 2007). La constatación de este hecho invalida la teoría funcionalista (Parsons, 1970), que pronosticaba que la expansión de la industrialización sustituiría los determinantes sociales de la trayectoria escolar (y laboral) por determinantes individuales (mérito). Actualmente, en sociología de la educación, existen dos grandes enfoques teóricos que intentan explicar la determinación social de la trayectoria escolar, las teorías de la reproducción social y las teorías de la elección racional. Las teorías de la reproducción social (Bourdieu y Passeron, 2001) consideran que el sistema escolar no es meritocrático ya que no reduce la desigualdad social entre los estudiantes, sino que la transforma en trayectorias escolares desiguales que generarán también trayectorias laborales desiguales pero socialmente legitimadas por un sistema escolar aparentemente meritocrático. Las teorías de la elección racional (Boudon, 1983; Breen 
y Goldthorpe, 2000) afirman que la trayectoria escolar está determinada por un análisis de costo-beneficio que realiza cada estudiante a partir de su posición social. Las diferentes trayectorias escolares se explican por los recursos con lo que cuenta cada clase social y sus diferentes costos de oportunidad.

En el contexto chileno predominan los trabajos descriptivo-cuantitativos que intentan medir el fenómeno y los trabajos explicativos que, aunque escasos, intentan explicarlo desde un enfoque próximo a la elección racional, siendo notable la ausencia del enfoque de la reproducción social.

Como ejemplo de trabajos próximos a las teorías de la elección racional, tenemos el estudio realizado por Donoso y Cancino (2007), donde sostienen que los estudiantes analizan los beneficios de permanecer en la institución. Si éstos son percibidos como mayores que los costos personales (esfuerzo y dedicación, entre otros), permanecerán estudiando, pero si detectan otras actividades que les generen mayores recompensas, los estudiantes tenderán a desertar. Por otro lado, argumentan que las características socioeconómicas de los estudiantes universitarios muestran que la rigidez de los currículos estudiantiles exige una dedicación exclusiva y muy demandante de apoyo financiero, hecho que constituye un autofiltro de ingreso en el sistema, es decir, que los estudiantes que prevén que no podrán dedicarse sólo a la universidad, optan por no ingresar.

En el mismo enfoque podemos ubicar al trabajo de Meller (2010), que afirma que la elección de universidad está determinada por el puntaje que obtienen los estudiantes en la PSU, existiendo en el sistema chileno universidades de alta, media y baja selectividad. Además, la elección de carrera, estaría determinada por la rentabilidad económica que obtienen sus egresados en el mercado laboral.

Un trabajo más descriptivo es el estudio que realizó el Consejo Superior de Educación de Chile en el año 2008 para conocer los niveles de retención de los estudiantes de educación superior. En este estudio, se observó que la deserción se concentra habitualmente en el primer año de las carreras, disminuyendo paulatinamente según avanzan en sus programas (Zapata y Tejeda, 2008).

En resumen, la investigación sobre la Educación Superior en Chile no ha analizado suficientemente los determinantes sociales de la trayectoria escolar, especialmente los determinantes de la elección de la carrera universitaria y los del abandono de la misma. En este sentido coincidimos con Donoso y Cancino (2007) cuando señalan la escasez de estudios sobre la trayectoria escolar de los estudiantes y critican que la orientación general de los trabajos realizados se centra en la mera cuantificación del fenómeno. 
Polis, Revista Latinoamericana, Volumen 14, No 42, 2015

\section{Caso de estudio}

La Universidad Católica del Norte (UCN), creada el año 1956, es una Institución privada de Derecho Público con aportes del Estado. La UCN fue la octava universidad que se fundó en Chile y la tercera de vocación Católica. Al año 2010 la UCN contaba con una matrícula de 10.077 estudiantes, de los cuales 9.458 están matriculados en 40 carreras de pregrado y 619 en programas de posgrado.

Las características de la UCN en términos de alumnos, académicos e infraestructura la posicionan en el grupo de universidades tradicionales regionales de tamaño medio. En este grupo de universidades se encuentran, junto a la UCN, la Universidad Austral de Chile, la Universidad de Talca y la Universidad Católica de Temuco. Dichas instituciones presentan indicadores similares tanto en la cantidad de alumnos como en sus características (ver tabla 2). Por lo anterior entendemos que la UCN puede representar un caso típico de universidad regional de tamaño medio.

Tabla 2: Indicadores de cuatro universidades tradicionales regionales (2009)

\begin{tabular}{|l|c|c|c|c|}
\hline Indicador & $\begin{array}{l}\text { U. Católica del } \\
\text { Norte (UCN) }\end{array}$ & $\begin{array}{l}\text { U. de } \\
\text { Talca }\end{array}$ & $\begin{array}{l}\text { U. Católica de } \\
\text { Temuco }\end{array}$ & $\begin{array}{l}\text { U. Austral } \\
\text { de Chile }\end{array}$ \\
\hline Alumnos Matriculados & 9.283 & 7.131 & 6.043 & 11.131 \\
\hline Puntaje Promedio PSU & 584 & 606 & 542 & 591 \\
\hline Promedio NEM & 5,9 & 6,2 & 5,7 & 6,0 \\
\hline $\begin{array}{l}\text { \% Alumnos de Colegios } \\
\text { Municipales }\end{array}$ & $28,5 \%$ & $46,5 \%$ & $39,8 \%$ & $41,4 \%$ \\
\hline $\begin{array}{l}\text { \% Alumnos Colegios Científico } \\
\text { Humanista }\end{array}$ & $78,9 \%$ & $76,7 \%$ & $78,2 \%$ & $82,0 \%$ \\
\hline $\begin{array}{l}\text { \% Matriculados Primera } \\
\text { Generación en Universidad }\end{array}$ & $68,1 \%$ & $76,0 \%$ & $79,0 \%$ & $69,4 \%$ \\
\hline $\begin{array}{l}\text { Tasa Retención Primer Año } \\
\text { Porcentaje JCE Académicos con } \\
\text { postgrado }\end{array}$ & $78,3 \%$ & $86,7 \%$ & $83,6 \%$ & $81,6 \%$ \\
\hline $\begin{array}{l}\text { \% Alumnas } \\
\text { (Promedio años 2005 al 2008) }\end{array}$ & $48,2 \%$ & $46,1 \%$ & $59,8 \%$ & $47,9 \%$ \\
\hline
\end{tabular}

Fuente: Elaboración propia a partir de RIDAI (2010)

\section{Propuesta teórica}

La sociología crítica de la educación nos muestra que el origen social de los alumnos determina en gran medida su trayectoria escolar y laboral. Los trabajos realizados por los sociólogos franceses Pierre Bourdieu y Jean- 
Claude Passeron durante la década de los 60 se suelen señalar como la piedra fundacional de esta línea de investigación, siendo La reproducción (1970/2001) la obra en donde se sintetizaron los hallazgos de trabajos anteriores y se presentó una teoría para analizar y explicar los efectos sociales del sistema educativo. La tesis principal de los autores es que el sistema educativo no cumple su misión declarada de lograr igualdad de oportunidades, sino que muy al contrario, sus efectos terminan reproduciendo y legitimando las diferencias sociales de los alumnos. La preocupación por el sistema educativo llevó más tarde a Bourdieu (1984/ 2008) al desarrollo de nuevas herramientas teóricas, como el concepto de campo social, entendiendo como tal a espacios sociales estructurados a partir de un conjunto de relaciones que se dan en su seno, que gozan de una autonomía relativa y de una lógica de funcionamiento propia. Así podemos hablar del campo escolar, del económico, del político o del artístico.

El presente artículo se propone pensar la trayectoria universitaria desde una perspectiva bourdieuniana, utilizando algunas de sus herramientas teórico-metodológicas.

\section{La desigualdad social como punto de partida}

Según Bourdieu, antes de ingresar en el sistema educativo, los futuros estudiantes ya tienen incorporada la desigualdad social que existe entre sus familias. Esta diferencia puede analizarse a partir del volumen global de capital con el que cuenta cada familia y la estructura de dicho capital (cuál es el tipo de capital dominante), éstos determinarán la clase social familiar.

Los tipos de capital (Bourdieu, 2001) determinantes para el rendimiento académico de los estudiantes son el capital económico y el capital cultural, mientras que el capital social con el que cuentan las familias es el más importante a la hora de rentabilizar el título académico en el mercado laboral.

El capital económico hace referencia al nivel de riqueza y renta que posee una familia. El volumen capital económico está directamente relacionado con la inversión escolar; los hijos de las familias con un mayor capital económico pasan más años en el sistema educativo (ingresan antes y salen más tarde) y pueden elegir centros de enseñanza de mayor calidad, que resultan inaccesibles para otras familias. La importancia del capital económico para explicar la cantidad de capital escolar adquirido por los estudiantes, aumenta en la medida en que lo hace la desigualdad del sistema educativo.

Por su parte, el capital cultural consiste en la posesión de una cantidad de conocimientos y habilidades socialmente reconocidos y valorados (Bourdieu, 2000: 143). Éste, es acumulado mediante la interiorización de una cultura determinada en el organismo biológico, 
este proceso de adquisición se produce principalmente en el seno familiar. El capital lingüístico (dominio del lenguaje) y el capital escolar (tipo de capital administrado, reconocido y valorado por el sistema educativo) son dos subtipos de capital cultural que poseen en distinto grado las familias y resultan determinantes para el éxito escolar de los estudiantes.

Otra propiedad importante de los estudiantes es el campo social en el que están insertos sus padres. El campo social funciona como un microcosmos relativamente autónomo que produce y reproduce su propia subcultura. En cada campo social se acumulan unas especies determinadas de capital que pueden ser transmitidas generacionalmente, facilitando el ingreso de los hijos en dicho campo. Las familias también pueden orientar a sus hijos para que abandonen su campo en el caso de que éste se encuentre en una situación histórica de decadencia, como ocurre con los miembros del campo agrario en sociedades en proceso de industrialización.

\section{La trayectoria escolar}

El sistema escolar no permite la reducción de la desigualdad social con la que ingresan los estudiantes, en vez de esto consigue, mediante una serie de operaciones, transformar el capital familiar (económico y sobre todo cultural) en el capital escolar del estudiante, reproduciendo así la desigualdad social inicial (Bourdieu y Passeron, 2001).

\section{La elección de carrera}

La elección de carrera está determinada al menos por dos propiedades fundamentales, la posición social (clase social y campo) y el género.

Las familias utilizan distintas estrategias para evitar el descenso de clase social de los hijos respecto a sus padres, dependiendo del volumen y la estructura de su capital (Bourdieu, 2006). Las posibles estrategias son:

La transmisión del capital de los padres a sus hijos para que éstos puedan conservar la posición social de los padres. Esta es la estrategia más sencilla y directa. Las familias que tienen un gran volumen de capital económico (empresarios) pueden transferirlo directamente a sus hijos. Por su parte, las familias que tienen un gran volumen de capital cultural (artistas, catedráticos, etc.) también pueden transmitirlo a sus hijos mediante un largo trabajo de inculcación en el ámbito familiar. El objetivo en ambos casos es la conservación del capital acumulado por la familia en la siguiente generación. El problema de la trasmisión directa del capital económico es que ha perdido legitimidad por atentar de una forma muy evidente contra el discurso meritocrático. Por ello, las clases 
dominantes se ven obligadas a utilizar otras estrategias más costosas como la reconversión del capital para poder asegurar su conservación.

En las condiciones sociales actuales el modo legítimo de reproducción ${ }^{1}$ del capital económico requiere la reconversión de este tipo de capital en capital cultural mediante la inversión escolar. Aunque esta estrategia de conservación del capital económico es más arriesgada que la de su trasmisión directa tiene la gran ventaja de ocultar o disimular la trasmisión y por lo tanto de legitimarla. Esta estrategia permite a los empresarios contratar a sus hijos y comenzar la transmisión del capital económico bajo la forma de altos salarios (como una herencia anticipada), además de inculcarles la lógica propia con la que opera el campo empresarial que les posibilitará en el futuro una posición relevante en dicho campo.

A las clases medias sin embargo no les sirven ni la estrategia de transmisión directa ni la de reconversión del capital, ya que éstas no aspiran a la conservación de su capital (o posición social) sino a incrementarlo. El objetivo aquí es el ascenso social intergeneracional. Con este fin, las clases medias deberán apostar por una inversión escolar intensiva ${ }^{2}$, que estará orientada a obtener la mayor rentabilidad económica del título académico en el mercado laboral.

Para el proletariado sin embargo, la estrategia de una inversión escolar intensiva (cursar carreras largas, caras y difíciles) resulta extremadamente arriesgada. Las condiciones de existencia de esta clase social le obligan a reducir al máximo las probabilidades de fracaso universitario. En el proletariado se impone la estrategia de la factibilidad o viabilidad, es decir, preferirán las carreras en las que tienen más posibilidades de éxito (subjetivización del las probabilidades objetivas), que suelen ser las carreras más desvaloradas socialmente (las más cortas, “fáciles” y económicas). Se trata de hacer de la necesidad virtud (Bourdieu, 2006; Martín Criado, 2004).

Además de lo dicho hasta ahora, habría que señalar que los hijos de las clases superiores se suelen orientar a profesiones cuya práctica está poco definida o estructurada, donde predominan los contenidos más abstractos y teóricos (artes o ciencias sociales) frente a las profesiones muy definidas donde predominan los contenidos técnicos (ingenierías). Cuanto más indefinida es una profesión más difícil resulta evaluar o seleccionar a sus profesionales a partir de la lógica escolar, siendo más probable una selección "natural” a partir de la afinidad con una cultura de clase. En estas profesiones, cuyo arquetipo podrían ser las de “asesor” o "consejero", el éxito estará determinado por el capital social y cultural adquirido en seno familiar y por la afinidad cultural (de clase) entre el profesional y los clientes. 
Polis, Revista Latinoamericana, Volumen 14, No 42, 2015

\section{Cuadro 1: Estrategias de las clases sociales}

\begin{tabular}{|c|c|c|c|}
\hline Clase social & Objetivo & Estrategias & $\begin{array}{l}\text { Definición } \\
\text { profesional }\end{array}$ \\
\hline $\begin{array}{l}\text { Clase Superior: } \\
\text { K. Económico }\end{array}$ & Conservación & Reconversión del K. & $\begin{array}{l}\text { Mayor Indefinición: } \\
\text { +abstracta, +teórica }\end{array}$ \\
\hline $\begin{array}{l}\text { Clase Superior: } \\
\text { K. Cultural }\end{array}$ & Conservación & $\begin{array}{l}\text { Transmisión directa e } \\
\text { Inversión }\end{array}$ & $\sqrt{5}$ \\
\hline Clases Medias & Incremento & Inversión intensiva & Mayor Definición: \\
\hline Proletariado & Incremento & Factibilidad & + concreta, + técnica \\
\hline
\end{tabular}

Fuente: Elaboración propia a partir de Bourdieu (2006)

La división de género del trabajo es un hecho social reconocido por todos los paradigmas sociológicos aunque estos ofrezcan distintas explicaciones y valoraciones. El patriarcado ${ }^{3}$, como matriz cultural cuasi-universal, construye y reconstruye mediante la socialización de género la identidad de género y los roles de género que permiten reproducir el orden de género ${ }^{4}$. Aunque la matriz patriarcal genera diferencias (por oposición) tanto en la identidad de género como en los roles de género, nosotros nos centraremos en las diferencias que están más relacionadas con la división del trabajo.

Mientras que la socialización de género prepara a los hombres para la producción social, las mujeres son preparadas para realizar el trabajo de reproducir las fuerzas productivas, lo que supone no sólo la reproducción biológica sino también la social; criar, alimentar, cuidar, limpiar, curar, escuchar, comprender, enseñar y ayudar son operaciones necesarias a realizar con los miembros de la familia, además de organizar y administrar la economía doméstica, esto es, los recursos disponibles para llevar a cabo el trabajo de reproducción social. Este trabajo se realiza en el espacio doméstico y privado, lo que facilita su ocultación y desconocimiento como trabajo en sí (objetivo o social), quedando reducido a un trabajo para sí (subjetivo o personal). La matriz patriarcal opera en todas las clases sociales y campos, en todos los territorios y en todas las generaciones (aunque se aprecia diferencias muy importantes entre ellas) siendo por tanto determinante en la orientación profesional de los futuros universitarios, donde se reproducirán sus oposiciones. 


\section{Cuadro 2: Las operaciones de producción y reproducción}

\begin{tabular}{|c|c|c|c|c|c|}
\hline \multicolumn{3}{|c|}{ Operaciones de reproducción } & \multicolumn{3}{|c|}{ Operaciones de producción } \\
\hline \multirow{4}{*}{ 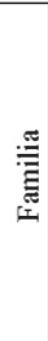 } & Criar & Curar & \multirow{3}{*}{ 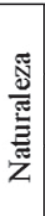 } & Dominar & Extraer \\
\hline & Alimentar & Enseñar & & Trasformar & Construir \\
\hline & Limpiar & Comprender & & Explotar & Analizar \\
\hline & Cuidar & Ayudar & 禀 & Proveer & Proteger \\
\hline$\frac{\grave{b}}{0}$ & \multicolumn{2}{|c|}{$\begin{array}{l}\text { Organizar y Administrar } \\
\text { el espacio domestico }\end{array}$} & $\frac{\grave{d}}{\grave{D}}$ & \multicolumn{2}{|c|}{$\begin{array}{l}\text { Organizary Administrar } \\
\text { el espacio público }\end{array}$} \\
\hline
\end{tabular}

Fuente: Elaboración propia a partir de Bourdieu (2003)

\section{La competencia escolar}

Además del capital lingüístico de los estudiantes es necesario conocer su grado de selección, es decir, la probabilidad objetiva que tenía el estudiante, a partir de su posición social, de llegar a la universidad (Bourdieu y Passeron, 2001). Así, los estudiantes pertenecientes al proletariado que consiguen llegar a la universidad, están más seleccionados que los pertenecientes a las clases superiores, pues su probabilidad objetiva de alcanzar la universidad era menor. Los estudiantes súper-seleccionados están mejor adaptados al trabajo escolar y son más resistentes al abandono universitario. La competencia escolar por tanto depende de la relación entre estas dos propiedades.

Al final, los efectos del sistema escolar son totalmente diferentes para las distintas clases sociales. Las clases dominantes al permanecer más tiempo en el sistema escolar, elegir los itinerarios más valorados y los centros más prestigiosos logran acumular una gran cantidad de capital escolar, que se utilizará (junto con el capital social familiar) para adquirir y legitimar una posición superior en la estructura ocupacional, presentando dicho capital escolar como un "logro personal" desvinculado del capital familiar. Para las clases dominadas, con una permanencia menor, elección de itinerarios más desvalorados y de centros menos prestigiosos, el paso del sistema escolar no les servirá para conseguir posiciones elevadas en la estructura ocupacional, pero sí para conocer y reconocer la posesión de capital escolar como el principio legítimo de desigualdad social (frente a la herencia de capital económico) y para conocer y reconocer la cultura de la clase dominante como una cultura superior diferente a la propia. 


\section{Críticas al enfoque reproductivo: las teorías de la Resistencia}

Sin negar la relevancia del enfoque reproductivo, los autores que se posicionan en las teorías de la resistencia (Bernstein, 1990; Apple, 1997; Willis, 1988; Giroux, 2001) han criticado desde una perspectiva más comprensiva diversos problemas que, entienden, presenta este enfoque, señalando además la necesidad de superarlo.

Estos autores consideran que el modelo reproductivo ha sobredimensionado el problema de la dominación, generando la imagen de un sistema escolar sin agencia, donde las relaciones entre los agentes escolares (maestros, alumnos y padres) estarían totalmente determinadas por la lógica del sistema capitalista, no habría por tanto, espacio para el conflicto, la creatividad o la resistencia. Por lo anterior, el modelo reproductivo sería políticamente pesimista respecto a la posibilidad de cambiar los efectos negativos del sistema escolar.

Otro problema que suelen señalar estos autores, sería la escasa contribución que las teorías reproductivas habrían realizado al conocimiento sobre las relaciones entre los agentes que participan del sistema escolar en contextos sociohistóricos concretos. Las teorías reproductivas, al prescindir del análisis empírico de la agencia, no podrían describir el proceso mediante el cual se impone la cultura dominante a las clases dominadas. Por ello, consideran que para el modelo reproductivo, el colegio seguiría siendo una caja negra, ya que sólo analiza los "input” y los “output”, pero no lo que ocurre dentro.

Para superar estos problemas y limitaciones, los teóricos de la resistencia desarrollaron un programa de investigación focalizado en las relaciones entre los agentes escolares (principalmente alumnos, padres y profesores), con un énfasis especial en las relaciones de conflicto y resistencia a los mecanismos socioculturales de reproducción. Para ello se privilegian las metodologías comprensivas: los trabajos etnográficos, los estudios culturales y los análisis cualitativos son los más utilizados.

Los resultados de este programa de investigación muestran que los agentes escolares no son sujetos pasivos en el proceso reproductivo, sino que pueden tener comportamientos oposicionistas, contestatarios o de resistencia, además pueden re-significar muchos elementos de los programas educativos oficiales. Estos trabajos también evidencian que el sistema escolar es relativamente autónomo respecto al poder político-económico, por lo que en ocasiones puede generar espacios con lógicas y discursos disfuncionales para el orden social. En resumen, ponen de manifiesto que pese a la asimetría de poder (que no es negada) existente entre los grupos sociales dominantes y los dominados (entre clases, etnias, géneros, etc.), los primeros nunca pueden dar por garantizada la transmisión e incorporación de su cultura por parte de los segundos, pues es un proceso más problemático que automático. 
Las teorías de la resistencia realizan una contribución imprescindible al conocimiento de los procesos reales (situados) al interior de la escuela, visibilizando y analizando las relaciones entre los agentes que participan en ella. Sin embargo, queremos señalar que algunas de las críticas que realizan al modelo reproductivo, especialmente su acusación de fatalismo social o sobrederminación reproductiva, son difíciles de sostener, al menos para la obra de Bourdieu. Como señala Beltrán (2014), Bourdieu hace especial énfasis en la naturaleza contingente de lo social, frente a la necesidad o el fatalismo. Cuando describe (denuncia) el proceso de reproducción social, es para dar cuenta de que sus causas no son naturales o ahistóricas, sino sociales, y por tanto cambiantes.

Bourdieu no pretende analizar los mecanismos de reproducción para resignarse a su poder, sino para impugnarlos. Y para ello se sirve de las propias herramientas que la escuela ofrece: la inteligencia de la razón frente a la astucia de la razón, la autoridad del lenguaje frente al imperialismo del discurso dominante, la posibilidad de ejercer una constante vigilancia epistemológica contra los muros mentales con los que los seres humanos nos sometemos a asedios y a cautiverios deliberados. Beltrán, 2014, p. 26

\section{Modelo de análisis ${ }^{5}$}

Proponemos un modelo de análisis diacrónico que trata de reconstruir la trayectoria escolar de los alumnos de la UCN relacionando sus propiedades sociales fundamentales con los momentos críticos (de paso) del sistema escolar,

I. Primer momento, las condiciones de existencia de los alumnos (posición social, género, estructura familiar y posición espacial) determinan el tipo de colegio en el que cursan la educación media.

II. Segundo momento, el tipo de colegio en el que estudia el alumno y su capital lingüístico (forma trasformada de sus condiciones de existencia) determinan el volumen de capital escolar conseguido al final de la educación media (rendimiento en la PSU).

III. Tercer momento, la estrategia de clase, el capital escolar (transformación escolar de las condiciones de existencia) y el género de los alumnos determinan el tipo de carrera que cursarán.

IV. Cuarto momento, el tipo de carrera que cursan los alumnos, su capital lingüístico y su grado de selección determinarán su competencia universitaria, esto es, su rendimiento académico y la probabilidad de abandono de la carrera. 


\section{Gráfico 2: Esquema del modelo}

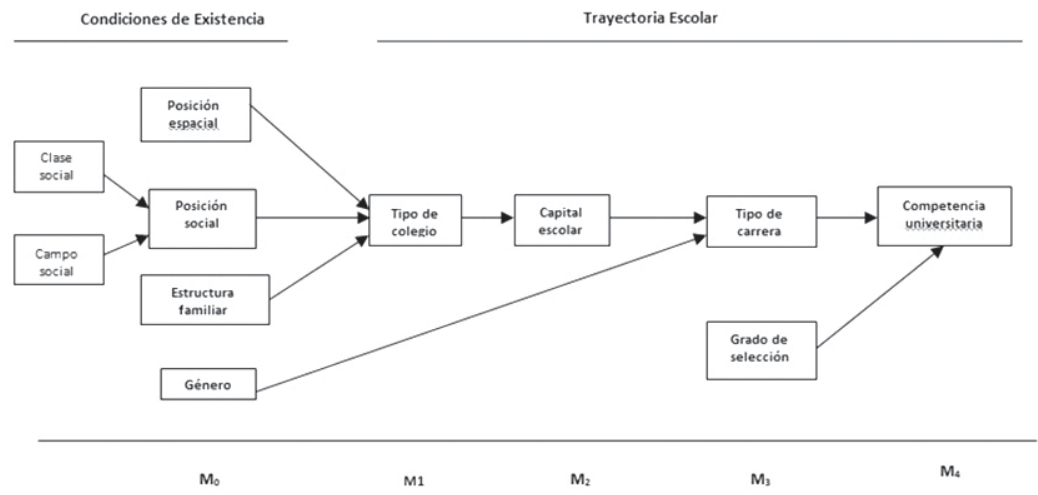

Fuente: elaboración propia.

\section{Metodología}

El objetivo de este trabajo es identificar y comprender los determinantes sociales de los últimos momentos de la trayectoria escolar, la elección de una carrera y la competencia universitaria. Para alcanzar dicho objetivo utilizaremos una estrategia cuantitativa de análisis multivariable y bivariable a partir de información secundaria proveniente de fuentes internas y externas a la UCN. Las bases de datos de fuentes externas provienen del Departamento de Evaluación, Medición y Registro Educacional de la Universidad de Chile (DEMRE) y las fuentes internas de la UCN de sus procesos de admisión (base ADMISIÓN) y desarrollo curricular de alumnos (base SIMBAD).

\section{Construcción de la base de datos}

A partir de las distintas fuentes se ha generado una única base de datos con la información relevante para nuestro trabajo. Los archivos que se utilizaron en el estudio incluyen:

a. DEMRE 2002-2008, Dos Bases de datos proporcionados por el DEMRE. La primera contiene los datos de 16.598 postulaciones realizadas entre los años 2002 y 2008. La segunda base de Datos de Beneficios DEMRE (Base_Beneficios_Becas) que contiene el registro de alumnos con sus respectivos datos de beneficios y becas recibidas.

b. Base de Datos de Admisión de alumnos 2002-2007, Contiene el detalle de los alumnos que ingresaron y se matricularon en la UCN 
en los años 2002 al 2007. La base cuenta originalmente con 9.974 registros

c. Rendimiento UCN 2002-2007, Contiene el detalle de numerosos registros de rendimiento semestral por alumno. Esta base cuenta con 13.807 registros.

Los datos disponibles en las fuentes anteriores nos permiten generar un conjunto de nuevas variables sociales, algunas de ellas a partir de la teoría de Bourdieu. Dichas variables son, Clase Social, Campo Social, Posición Social, Estructura Familiar, Tipo de Carrera, Posición espacial, Tamaño Comuna, Situación del Alumno y Sede universitaria.

Finalmente, después de un proceso de limpieza y ajuste entre las distintas fuentes, decidimos seleccionar a los alumnos que habían ingresado en la UCN en el periodo 2002-2007, eliminando al resto. La muestra final de estudiantes que utilizamos para nuestro trabajo fue de 6.335.

\section{Análisis de datos}

Para analizar los datos utilizaremos coeficientes de localización y árbol de clasificación y regresión ${ }^{6}$. La elección de dichas técnicas está determinada por los objetivos de la investigación y por el tipo de variables con el que se representan a las distintas propiedades sociales; las variables independientes serán ordinales y nominales (categóricas) y las variables dependientes serán nominales.

\section{El coeficiente de localización}

El coeficiente de localización es un indicador que permite estimar en qué medida una determinada categoría A se encuentra sub o sobrerrepresentada en B con respecto a lo que cabría esperar de su participación en el conjunto de la población (Isard, 1971). Este coeficiente se calcula a partir de la siguiente expresión,

$$
Q_{A, B}=\frac{\frac{C_{A B}}{C_{B}}}{\frac{C_{A}}{C}}
$$

Donde $\frac{C_{A B}}{C_{B}}$ es la participación de A en B y $\frac{C_{A}}{C}$ es la participación de A en el total de la población.

Un valor de coeficiente de localización igual a 1 implica que la participación de la categoría A en B es igual a su distribución en el conjunto de la población. Valores por encima de 1 suponen una sobrerrepresentación de dicha categoría y lo contrario cuando los valores son inferiores a 1. El resultado de este indicador también puede interpretase en términos probabilísticos. 


\section{Árbol de clasificación y regresión}

El árbol de clasificación y regresión (CART) es una técnica de análisis de segmentación que genera un modelo de clasificación y predicción para una variable dependiente, es por tanto una técnica de dependencia (Escobar, 2007). Como el resto de técnicas de segmentación, el procedimiento CART agrupa a los casos más similares entre sí, en grupos mutuamente excluyentes, a partir de un rasgo común, su respuesta a la variable dependiente. Este procedimiento, a diferencia de otras técnicas de segmentación, nos permite además cuantificar la importancia de cada una de las variables independientes identificas y validar el modelo predictivo con una submuestra. En esta técnica tanto la variable dependiente como las variables independientes son nominales.

El resultado del análisis de segmentación se representa gráficamente mediante un árbol invertido, en cuya "raíz" se encuentra el conjunto de la muestra distribuida a partir de la variable dependiente (nodo 0) y en los niveles inferiores la muestra se divide formando "ramas" en distintos grupos (nodos) a partir de las variables independientes en orden de importancia decreciente. Los grupos (nodos) del último nivel serían las "hojas" del árbol. Por tanto, la variable independiente (pueden ser varias) que aparece en el primer nivel del árbol segmentando la muestra es la que tiene un mayor poder predictivo, mientras que la que aparece en el último nivel, aún siendo significativa, es la menos importante.

\section{Resultados}

Los 6.335 estudiantes en la muestra se distribuyen en 34 carreras que se agruparon en las áreas de Ingeniería, Ciencias ambientales, Ciencias sociales, Pedagogías y Ciencias de la salud ${ }^{7}$. La tabla 3 presenta en forma resumida los atributos socio-demográficos de la muestra de estudiantes de la Universidad Católica del Norte utilizada en este estudio. En términos de género, los hombres en la muestra representan una proporción levemente mayor que las mujeres, 54,9\% en total. El tipo de colegio del que provienen los estudiantes en la muestra fue mayoritariamente de colegios particulares subvencionados, 43,8\%, seguida de los colegios municipales, 34,6\%, y en menor medida estuvieron representados los colegios privados, 21,6\%. Esta realidad es similar a la distribución de estudiantes por tipo de colegio en Chile, presentada por el Consejo Nacional de Educación (MINEDUC, 2010).

Respecto a su condición social, la clase media está representada mayoritariamente en la muestra, con el 55\% del total de estudiantes, la clase social proletaria representa al $25,2 \%$ del total, mientras que la clase superior, la más acomodada, representa sólo el 19,8\% del total. Dado que no conocemos la distribución por clases sociales de los estudiantes de educación superior en Chile, no nos es posible comparar este resultado con la realidad nacional. 
Tabla 3: Características socio-demográficas de la población de estudio

\begin{tabular}{|c|c|c|c|}
\hline Variable & Descripción & Frecuencia & $\%$ \\
\hline Genero & $\begin{array}{l}\text { Hombres } \\
\text { Mujeres }\end{array}$ & $\begin{array}{l}3.479 \\
2.856\end{array}$ & $\begin{array}{l}54,9 \\
45,1\end{array}$ \\
\hline Tipo de Colegio & $\begin{array}{l}\text { Privado } \\
\text { Subvencionado } \\
\text { Municipal }\end{array}$ & $\begin{array}{l}1.367 \\
2.773 \\
2195\end{array}$ & $\begin{array}{l}21,6 \\
43,8 \\
34,6\end{array}$ \\
\hline Clase Social & $\begin{array}{l}\text { Superiores } \\
\text { Medias } \\
\text { Proletariado }\end{array}$ & $\begin{array}{l}1.255 \\
3.482 \\
1.598\end{array}$ & $\begin{array}{l}19,8 \\
55,0 \\
25,2\end{array}$ \\
\hline Posición Social & $\begin{array}{l}\text { CS: Empresarial } \\
\text { CS: Privado } \\
\text { CS: Público } \\
\text { CS: Educación } \\
\text { CM: Empresarial Agro } \\
\text { CM: Empresarial } \\
\text { CM: Privado } \\
\text { CM: Público } \\
\text { CM: Educación } \\
\text { P: Agro } \\
\text { P: Autónomo } \\
\text { P: No cualificado } \\
\text { P: Cualificado }\end{array}$ & $\begin{array}{l}20 \\
867 \\
320 \\
48 \\
42 \\
447 \\
1839 \\
662 \\
492 \\
130 \\
139 \\
466 \\
863\end{array}$ & $\begin{array}{l}, 3 \\
13,7 \\
5,1 \\
, 8 \\
, 7 \\
7,1 \\
29,0 \\
10,4 \\
7,8 \\
2,1 \\
2,2 \\
7,4 \\
13,6\end{array}$ \\
\hline
\end{tabular}

Fuente: Base de Datos de Admisión de alumnos 2002-2007, Universidad Católica del Norte

A continuación presentaremos un resumen de los resultados obtenidos en los dos primeros momentos del modelo de análisis, para posteriormente exponer, de forma más detallada, los resultados de los dos últimos momentos. 


\section{Determinantes sociales del tipo de colegio y del capital escolar, momentos I y II}

En el primer momento de nuestro modelo de análisis pudimos verificar que la posición social y la posición espacial de los alumnos determinaron el tipo de colegio (privado, subvencionado o municipal) en el que cursaron la enseñanza media. Así, los alumnos que pertenecen a posiciones sociales y espaciales privilegiadas tienen una mayor probabilidad de estudiar en colegios privados, los que ocupan posiciones intermedias en colegios subvencionados y los que ocupan posiciones inferiores en colegios municipales (ORDHUM Y CIGTE, 2013).

En el segundo momento del análisis, pudimos comprobar cómo la posición social y, muy especialmente, el tipo de colegio (transformación escolar del capital económico familiar) en el que los alumnos cursaron la educación media, determinaron el capital escolar (PSU) que obtuvieron al finalizar dicha etapa escolar. Observamos cómo los alumnos que pertenecen a las clases superiores y a los campos culturales (educativo y público) obtienen sistemáticamente más capital escolar que los pertenecientes al proletariado y los campos económicos (privado, empresarial y agro) para todos los tipos de colegio. También verificamos que los alumnos que cursan la educación media en los colegios municipales, obtienen sistemáticamente menos capital escolar que los que lo hacen en colegios subvencionados y privados y, a diferencia de otros países ${ }^{8}$, esto es independiente de la posición social de los alumnos. Además, pudimos observar que la diferencia en el capital escolar obtenido por los alumnos de distinto origen social se reduce de forma muy significativa cuando aumenta la calidad escolar ${ }^{9}$ del colegio (aunque nunca desaparece), es decir, la diferencia se maximiza en los colegios municipales y se minimiza en los colegios privados. La importancia del tipo de colegio para nuestra población de estudio se puede explicar por la enorme distancia social que existe actualmente en Chile, tanto entre clase sociales, como entre recursos escolares disponibles para cada clase (ORDHUM Y CIGTE, 2013).

\section{Determinantes sociales de la elección del tipo de carrera, momento III}

Hemos construido los coeficientes de localización de dos de las propiedades sociales que componen las condiciones de existencia de los alumnos, el género y la posición social, para conocer su incidencia probabilística sobre la elección del tipo de carrera.

\section{El género como determinante del tipo de carrera}

El género de los alumnos determina de forma importante al tipo de carrera que cursarán en la universidad. Observamos que los hombres tienen una mayor de probabilidad (30\% más) de elegir Ingenierías, frente a las mujeres, que eligen casi dos veces menos este tipo de carreras. Vemos también como las mujeres tienen una mayor probabilidad de elegir Pedagogías y Ciencias de la Salud (40\% más) y, en menor medida, Ciencias Sociales 
(20\% más). Por su lado, los hombres presentan la situación contraria. En resumen, las mujeres están sobrerrepresentadas en las Pedagogías, las Ciencias de la Salud y, en menor medida, en las Ciencias Sociales mientras que los hombres lo están en las Ingenierías.

\section{Tabla 4: Coeficiente de localización del género para el tipo de carrera}

\begin{tabular}{|c|c|c|c|c|c|}
\hline \multirow[b]{2}{*}{ Género } & \multicolumn{5}{|c|}{ Tipos de carrera } \\
\hline & Ingenierías & Ciencias Ambientales & Ciencias Sociales & Pedagogías & Ciencias Salud \\
\hline Hombres & 1,3 & 0,9 & 0,8 & 0,7 & 0,7 \\
\hline Mujeres & 0,6 & 1,1 & 1,2 & 1,4 & 1,4 \\
\hline
\end{tabular}

Fuente: Elaboración propia

\section{La posición social como determinante del tipo de carrera}

Observado los coeficientes de localización podemos ver como las clases superiores huyen de las Pedagogías y de las Ciencias de Ambientales (carreras con mínima valoración social ${ }^{10}$ ), apostando por las Ciencias de la Salud y las Ciencias Sociales (carreras con máxima valoración social). Por su parte, el proletariado huye de las Ingenierías (máximo grado de dificultad) y de las Ciencias de la Salud (máxima exigencia de entrada) y en menor media de las Ciencias Sociales (carreras muy teóricas y con profesiones poco definidas), concentrándose en las Ciencias Ambientales y en las Pedagogías (mínima exigencia de entrada y valoración social, con profesiones bien definidas).

Las posiciones sociales pertenecientes al campo empresarial (hijos de empresarios) huyen tanto de las carreras devaluadas (Pedagogías y Ciencias Ambientales) como de las “difíciles” (Ingenierías), concentrándose, sobre todo los varones, en las carreras que permiten facilitar la transferencia intergeneracional del capital económico (Ciencias Sociales). Las posiciones pertenecientes al campo privado (hijos de empleados en empresas privadas) apuestan por las Ingenierías, por ser éstas, probablemente, las profesiones mejor valoradas (tanto en términos de ingresos como de estatus) en dicho campo social. Las posiciones que pertenecen a los campos culturales (público y educativo) están más próximas a las Ciencias de la Salud y a las Ciencias Sociales, carreras bien valoras que facilitan la trasmisión familiar del capital cultural. Por último, las posiciones que pertenecen al campo agrario rechazan las Ingenierías (carreras “difíciles” y muy alejadas de su campo social) y apuestan claramente por las Ciencias Ambientales, carreras que deberán permitir el ascenso social sin abandonar el campo familiar (misma estrategia que tiene el campo privado con las Ingenierías). 
Polis, Revista Latinoamericana, Volumen 14, No 42, 2015

Tabla 5: Coeficiente de localización de la posición social para el tipo de carrera

\begin{tabular}{|c|c|c|c|c|c|}
\hline \multirow[b]{2}{*}{ Posición social } & \multicolumn{4}{|c|}{ Tipos de carrera } & \multirow[b]{2}{*}{$\begin{array}{c}\text { Ciencias } \\
\text { Salud }\end{array}$} \\
\hline & Ingenierías & $\begin{array}{c}\text { Ciencias } \\
\text { Ambientales }\end{array}$ & $\begin{array}{l}\text { Ciencias } \\
\text { Sociales }\end{array}$ & Pedagogías & \\
\hline CS: Empresarial & 0,6 & 0,9 & 1,6 & 0,0 & 1,3 \\
\hline CS: Privado & 1,1 & 0,8 & 1,0 & 0,4 & 1,1 \\
\hline CS: Público & 0,8 & 0,8 & 1,2 & 0,7 & 1,5 \\
\hline CS: Educación & 1,0 & 0,8 & 1,2 & 0,4 & 1,1 \\
\hline $\mathrm{CM}$ : Empresarial agro & 0,6 & 1,5 & 1,0 & 0,9 & 1,4 \\
\hline CM: Empresarial & 0,9 & 1,0 & 1,2 & 0,8 & 1,0 \\
\hline CM: Privado & 1,1 & 1,0 & 1,0 & 1,1 & 0,9 \\
\hline CM: Público & 1,0 & 1,0 & 1,0 & 0,9 & 1,0 \\
\hline CM:Educación & 0,8 & 0,9 & 1,1 & 1,0 & 1,3 \\
\hline P: Agro & 0,5 & 2,1 & 1,0 & 1,6 & 0,8 \\
\hline P: Autónomo & 0,8 & 1,4 & 0,8 & 1,7 & 1,1 \\
\hline P: No Cualificado & 0,9 & 1,1 & 1,0 & 1,6 & 0,9 \\
\hline P: Cualificado & 1,1 & 1,1 & 0,8 & 1,2 & 0,9 \\
\hline
\end{tabular}

Fuente: Elaboración propia

\section{Análisis de segmentación para el tipo de carrera}

Realizaremos un árbol de clasificación y regresión para agrupar a los alumnos a partir del tipo de carrera universitaria elegida (variable dependiente) y para conocer la importancia de las distintas propiedades sociales.

Tabla 6 a: Riesgo

\begin{tabular}{|l|l|l|}
\hline Método & Estimación & $\begin{array}{l}\text { Error } \\
\text { típico }\end{array}$ \\
\hline $\begin{array}{l}\text { Resustitución } \\
\begin{array}{l}\text { Validación } \\
\text { cruzada }\end{array}\end{array}$ &, 574 &, 006 \\
\hline
\end{tabular}

Fuente: Elaboración propia 
Tabla 6 b: Importancia de la variable independiente

\begin{tabular}{|l|l|l|}
\hline $\begin{array}{l}\text { Variable } \\
\text { independiente }\end{array}$ & Importancia & $\begin{array}{l}\text { Importancia } \\
\text { normalizada }\end{array}$ \\
\hline Género &, 025 & $100,0 \%$ \\
Posición espacial &, 013 & $53,1 \%$ \\
Nota PSU (media) &, 012 & $48,3 \%$ \\
Tipo de Colegio &, 004 & $15,0 \%$ \\
Campo Social &, 002 & $9,7 \%$ \\
Clase Social &, 002 & $6,3 \%$ \\
Estructura Familiar &, 001 & $3,9 \%$ \\
\hline
\end{tabular}

Fuente: Elaboración propia

El árbol generado tiene capacidad para predecir acertadamente el 42,6\% de los casos (riesgo, 0,578) y utiliza sólo tres de las variables introducidas; el género, el capital escolar de los alumnos (nota en la PSU) y la posición espacial (distancia de la residencia de los alumnos con la ciudad universitaria).

El género de los alumnos se presenta, con diferencia, como la variable más importante para explicar el tipo de carrera elegida. Los hombres tienen más del doble de probabilidad que las mujeres de elegir una Ingeniería (48\% hombres vs. 21\% mujeres), mientras que las mujeres tiene el doble de probabilidad que los hombres de elegir Pedagogías (3,4\% hombres vs. 7,2\% mujeres) o Ciencias de la Salud (10,5\% hombres vs. 20,6\% mujeres). Comprobamos como, siguiendo la matriz patriarcal, los alumnos se dirigen a profesiones relacionadas con trabajos de producción (como las Ingenierías) y las alumnas a profesiones relacionadas con trabajos de reproducción (como las Ciencias de Salud y las Pedagogías).

En el segundo nivel y con mucha menos importancia predictiva que el género (48,3\%) tenemos el capital escolar de los alumnos (nota de la PSU). Los alumnos y las alumnas con poco capital escolar (bajo la media PSU) tienen más del doble de probabilidad de cursar Ciencias Ambientales y Pedagogías, mientras que los que cuentan con alto capital escolar (sobre la media PSU) tienen el triple de probabilidad de cursar una carrera de Ciencias de la Salud y una probabilidad ligeramente mayor de cursar Ciencias Sociales. Estos resultados son consistentes con la teoría bourdieuniana, los alumnos con alto capital escolar eligen carreras con alta valoración social mientras que los alumnos con poco capital escolar eligen las carreras más devaluadas.

En el último nivel, pero con mayor importancia que la variable anterior (el 53,1\% del género) tenemos la residencia (distancia con el centro universitario). Los alumnos y alumnas con alto capital escolar, cuyas familias residen en la ciudad en la que estudian tienen una mayor probabilidad de estudiar Pedagogías (hasta tres veces mayor en las alumnas), Ciencias Am- 
bientales e Ingenierías que los alumnos desplazados. Frente a ellos, los alumnos y alumnas desplazados tienen una mayor probabilidad de estudiar Ciencias de la Salud (el triple para las alumnas y el doble para los alumnos) y en menor medida Ciencias Sociales. En el caso de los alumnos y alumnas con bajo capital escolar observamos como estas diferencias se mantienen sólo para las carreras de Pedagogía y Ciencias de la Salud, los extremos opuestos en valoración social y exigencia de entrada. Comprobamos por tanto, que los alumnos y alumnas desplazados y con alto capital escolar, para los que estudiar supone una mayor inversión, optan por carreras de alta valoración social y exigencia de entrada (Ciencias de la Salud y en menor medida Ciencias Sociales), mientras que los alumnos y alumnas originarios de la ciudad en la que estudian, optan en mayor medida por carreras con baja valoración social y exigencia de entrada (Pedagogías, Ciencias Ambientales y en menor medida Ingenierías).

En resumen, la elección de la carrera universitaria que cursan los alumnos está determinada en primer lugar por su género (división del trabajo propia de la matriz patriarcal); en segundo lugar, por su capital escolar (trasformación escolar de su posición social y de los recursos locales disponibles) y en tercer lugar por su residencia (distancia con la universidad). La posición social (campo y clase social) y el tipo de colegio (transformación escolar del capital económico) tienen menor relevancia este momento (el 16\% y el $15 \%$ respecto al género) al haber sido transformadas en un momento anterior (educación media) en capital escolar.

\section{Gráfico 3: Determinantes del tipo de carrera}

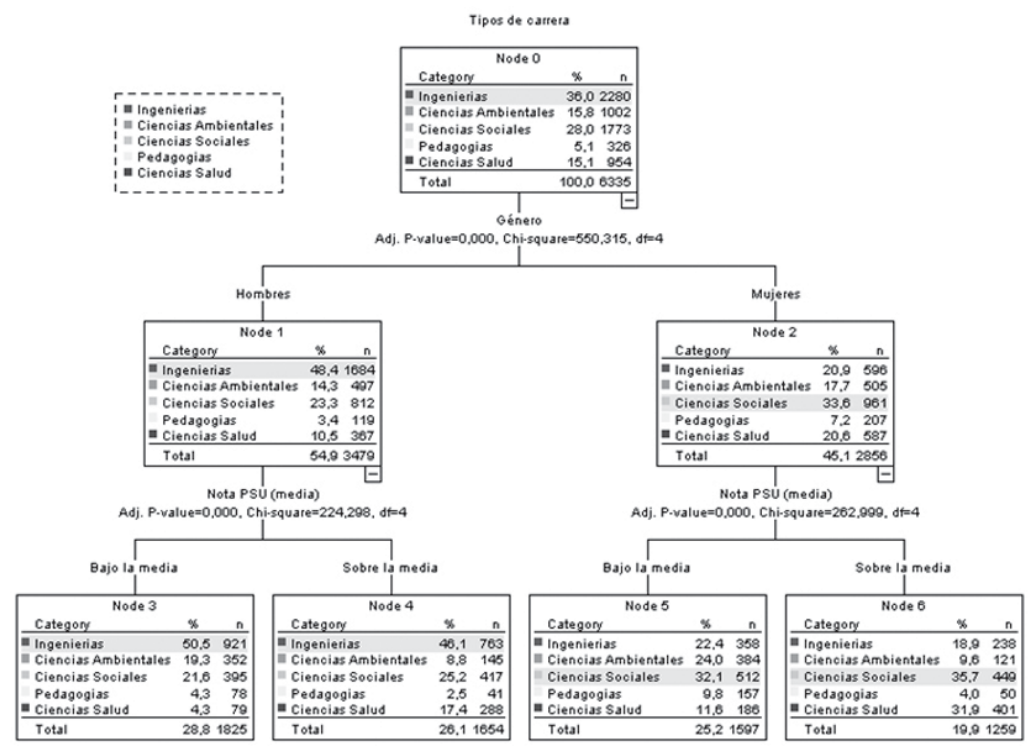

Fuente: Elaboración propia 


\section{Determinantes sociales de la competencia universitaria, IV momento}

Este momento hace referencia a cómo el capital escolar de los alumnos (transformación escolar de sus condiciones de existencia), el grado de selección que han sufrido durante la trayectoria escolar y el tipo de carrera elegida (elección estratégica determinada por las condiciones de existencia) determinan la competencia universitaria de los estudiantes (variable dependiente).

Se han construido los coeficientes de localización del tipo de carrera y de la posición social para conocer su incidencia probabilística sobre la competencia universitaria de los alumnos. Se trata de conocer el grado de dificultad de cada tipo de carrera (riesgo de abandono) y la importancia que tienen para cada posición social dos propiedades sociales que actúan como fuerzas opuestas; el capital escolar y el grado de selección.

\section{La elección de carrera como determinante de la competencia universitaria}

El tipo de la carrera que cursan los alumnos resulta determinante para su competencia universitaria. Las Ingenierías son las carreras con un mayor riesgo de abandono; seguidas por las Ciencias Ambientales, las Ciencias Sociales, las Pedagogías y las Ciencias de la Salud. No abordaremos en este artículo las razones de estas diferencias, que, según Bourdieu, habría que buscar en la construcción histórica del campo universitario chileno y en la posición de las distintas carreras en dicho campo. Para nuestro objetivo basta con confirmar que efectivamente cada tipo de carrera tiene un riesgo diferente de abandono que nos permite ordenarlas por grado de dificultad y que dicho orden, como podemos comprobar en las tablas 7 y 8 , es independiente del género o del capital escolar de los alumnos.

\section{Tabla 7: Coeficientes de localización del tipo de carrera por género en la situación de los alumnos}

\begin{tabular}{|llcc|}
\hline \multirow{6}{*}{ Género } & Tipos de carrera & $\begin{array}{c}\text { Situación } \\
\text { Permanencia }\end{array}$ & Abandono \\
\hline Hombres & Ingenierías & 0,8 & 1,2 \\
& Ciencias Ambientales & 1,0 & 1,0 \\
& Ciencias Sociales & 1,1 & 0,9 \\
& Pedagogías & 1,3 & 0,8 \\
& Ciencias Salud & 1,6 & 0,5 \\
\hline Mujeres & Ingenierías & 0,7 & 1,5 \\
& Ciencias Ambientales & 0,9 & 1,1 \\
& Ciencias Sociales & 1,1 & 0,9 \\
& Pedagogías & 1,0 & 1,0 \\
& Ciencias Salud & 1,4 & 0,5 \\
\hline
\end{tabular}

Fuente: Elaboración propia 
Tabla 8: Coeficientes de localización del tipo de carrera por capital escolar en la situación de los alumnos

\begin{tabular}{|llcc|}
\hline PSU & Tipo de carrera & $\begin{array}{c}\text { Situación } \\
\text { Permanencia }\end{array}$ & Abandono \\
\hline Bajo la media & Ingenierías & 0,6 & 1,2 \\
& Ciencias Ambientales & 1,0 & 1,0 \\
& Ciencias Sociales & 1,2 & 0,9 \\
& Pedagogías & 1,3 & 0,8 \\
& Ciencias Salud & 1,7 & 0,5 \\
\hline Sobre la media & Ingenierías & 0,8 & 1,3 \\
& Ciencias Ambientales & 1,0 & 1,0 \\
& Ciencias Sociales & 1,0 & 1,0 \\
& Pedagogías & 1,1 & 0,8 \\
& Ciencias Salud & 1,3 & 0,6 \\
\hline
\end{tabular}

Fuente: Elaboración propia

\section{Posición social como determinante de la competencia universitaria}

Como podemos observar en las siguientes tablas, hay diferencias importantes en el riesgo que tienen las distintas posiciones sociales de abandonar la carrera. En el caso de los alumnos varones, el riesgo de abandono en las carreras de Ciencias de la Salud y Ciencias Sociales (máximo estatus y exigencia de entrada), puede ser explicado por el efecto de selección, es decir, que los alumnos pertenecientes a las posiciones sociales con menos probabilidad de llegar a la universidad (alumnos sobre-seleccionados), tienen un menor riesgo de abandonar la carrera, mientras que los alumnos pertenecientes a posiciones sociales con alta probabilidad de llegar a la universidad (alumnos infra-seleccionados), tienen un riesgo mayor de abandonar la carrera. La permanencia en las carreras de Ciencias Ambientales parece estar explicada, además de por el efecto de selección, por un efecto de campo, ya que observamos que las posiciones sociales pertenecientes al campo agrario (hijos de los empresarios y trabajadores agrarios) tienen un riesgo más bajo de abandonar dichas carreras. Por último, la permanencia en las Ingenierías (máximo riesgo de abandono) puede ser explicada por el capital lingüístico de los alumnos, es decir, los alumnos que provienen de posiciones sociales más altas tienen menor riesgo de abandono y viceversa. 
Tabla 9: Coeficientes de localización de la posición social de los alumnos varones en la situación de permanencia

\begin{tabular}{|c|c|c|c|c|c|}
\hline \multirow[b]{2}{*}{ Posición social } & \multicolumn{5}{|c|}{ Situación de permanencia de los alumnos } \\
\hline & Ingenierías & Ambientales & Sociales & Pedagogías & Salud \\
\hline CS: Empresarial & 0,0 & 0,0 & 0,3 & & 0,7 \\
\hline CS: Privado & 1,1 & 1,0 & 1,0 & 1,5 & 0,9 \\
\hline CS: Público & 1,2 & 0,9 & 0,8 & 3,1 & 0,9 \\
\hline CS: Educación & 1,5 & 0,0 & 1,3 & & 0,9 \\
\hline CM: Empresarial Agro & 1,7 & 1,2 & 0,9 & 0,0 & 1,4 \\
\hline CM: Empresarial & 1,1 & 1,3 & 0,9 & 1,5 & 0,9 \\
\hline CM: Privado & 0,9 & 0,8 & 1,1 & 1,1 & 1,1 \\
\hline CM: Público & 1,0 & 1,1 & 1,0 & 0,7 & 1,1 \\
\hline CM: Educación & 1,1 & 1,1 & 1,1 & 0,6 & 1,0 \\
\hline P: Agro & 0,7 & 1,7 & 1,1 & 1,2 & 1,2 \\
\hline P: Autónomo & 0,4 & 1,1 & 0,8 & 1,8 & 1,4 \\
\hline P: No cualificado & 1,1 & 0,9 & 1,0 & 0,5 & 1,0 \\
\hline P: Cualificado & 1,0 & 1,0 & 1,0 & 1,4 & 0,9 \\
\hline
\end{tabular}

Fuente: Elaboración propia

Para el caso de las alumnas, el riesgo de abandono en las carreras de Ciencias de la Salud también puede ser explicado por el efecto de selección. Sin embargo, a diferencia de los varones, la permanencia en las carreras de Ciencias Ambientales y de Ciencias Sociales está relacionada, al igual que en las Ingenierías, por el capital lingüístico.

Tabla 10: Coeficientes de localización de la posición social de las alumnas en la situación de permanencia

\begin{tabular}{|c|c|c|c|c|c|}
\hline \multirow[b]{2}{*}{ Posición social } & \multicolumn{5}{|c|}{ Situación de permanencia de las alumnas } \\
\hline & Ingenierías & Ambientales & Sociales & Pedagogías & Salud \\
\hline CS: Empresarial & 2,7 & 2,0 & 0,6 & & 0,7 \\
\hline CS: Privado & 1,0 & 1,3 & 1,0 & 0,9 & 1,0 \\
\hline CS: Público & 1,5 & 0,9 & 1,0 & 1,0 & 0,9 \\
\hline CS: Educación & 2,2 & 2,0 & 1,3 & 0,0 & 1,3 \\
\hline CM: Empresarial Agro & 1,4 & 1,3 & 1,0 & & 1,3 \\
\hline CM: Empresarial & 1,0 & 0,8 & 0,9 & 0,7 & 1,0 \\
\hline CM: Privado & 1,0 & 1,0 & 1,1 & 1,1 & 1,0 \\
\hline CM: Público & 1,1 & 1,0 & 0,9 & 1,2 & 1,0 \\
\hline CM: Educación & 1,1 & 0,9 & 1,1 & 0,9 & 1,0 \\
\hline P: Agro & 0,0 & 0,8 & 0,8 & 0,7 & 1,2 \\
\hline P: Autónomo & 1,1 & 0,9 & 0,7 & 0,9 & 1,1 \\
\hline P: No cualificado & 0,6 & 0,9 & 1,1 & 0,6 & 1,1 \\
\hline P: Cualificado & 1,0 & 1,1 & 0,9 & 1,4 & 0,9 \\
\hline
\end{tabular}

Fuente: Elaboración propia 
Resumiendo, el efecto de selección puede explicar la permanencia tanto de los alumnos como de las alumnas en las carreras de Ciencias de la Salud (máxima valoración social y exigencia de entrada), mientras que el capital lingüístico puede explicar la permanecía, también de ambos géneros, en las Ingenierías (máximo riego de abandono). Además, hemos identificado un efecto de campo, que afecta a los alumnos en las carreras de Ciencias Ambientales. Puede que estos alumnos realicen un sobre-esfuerzo de permanencia en dichas carreras, respondiendo a las expectativas de las familias agrarias, que podrían focalizan con más intensidad que el resto de los campos sociales, su reproducción económica en los hijos varones. Por otro lado, tenemos el caso de las Pedagogías, donde no encontramos ninguno de efectos estudiados.

\section{Cuadro 3: Efectos de posición social}

\begin{tabular}{|l|l|l|}
\hline Efectos & Alumnos & Alumnas \\
\hline Efecto de selección: & $\begin{array}{l}\text { Ciencia de la Salud } \\
\text { Ciencias sociales } \\
\text { Ciencias Ambientales }\end{array}$ & Ciencia de la Salud \\
\hline Efecto de campo: & Ciencias Ambientales & \\
\hline Capital lingüístico: & Ingenierías & $\begin{array}{l}\text { Ingenierías } \\
\text { Ciencias Ambientales } \\
\text { Ciencias sociales }\end{array}$ \\
\hline Sin efectos: & Pedagogías & Pedagogías \\
\hline
\end{tabular}

Fuente: Elaboración propia

\section{Análisis de segmentación para la competencia universitaria}

Utilizaremos un árbol de clasificación y regresión para identificar las propiedades sociales más relevantes para determinar la competencia universitaria $^{11}$ (variable dependiente) y para agrupar a nuestra población a partir de este criterio.

Tabla 11 a: Riesgo

\begin{tabular}{|l|l|l|}
\hline Método & Estimación & Error típico \\
\hline Re-sustitución &, 369 &, 006 \\
Validación cruzada &, 376 &, 006 \\
\hline
\end{tabular}

Fuente: Elaboración propia 
Tabla 11 b: Importancia de la variable independiente

\begin{tabular}{|l|l|l|}
\hline Variable independiente & Importancia & Importancia normalizada \\
\hline Tipos de carrera &, $\mathbf{0 4 8}$ & $\mathbf{1 0 0 , 0 \%}$ \\
Nota PSU ponderada & $\mathbf{, 0 3 3}$ & $\mathbf{6 9 , 2 \%}$ \\
Género &, $\mathbf{0 0 9}$ & $\mathbf{1 9 , 7 \%}$ \\
Posición Social &, 001 & $\mathbf{1 , 6 \%}$ \\
Estructura Familiar &, 001 & $1,2 \%$ \\
Posición espacial &, 000 &, $4 \%$ \\
Tipo de Colegio &, 000 &, $3 \%$ \\
Tamaño Comuna & $1,95 \mathrm{E}-005$ &, $0 \%$ \\
\hline
\end{tabular}

Fuente: Elaboración propia

El modelo generado por el árbol de clasificación es capaz de predecir el $63 \%$ de los casos (riesgo, 0,376), siendo más exitoso con los casos de permanencia $(77,4 \%)$ que con los de abandono (49,3\%). Identifica cinco variables independientes como determinantes, siendo la más importante el tipo de carrera que cursan los alumnos. Le siguen en orden de importancia el capital escolar (nota en la PSU), el género, la posición social y la estructura familiar.

En el primer nivel, el árbol utiliza el capital escolar para clasificar a los alumnos, siendo más probable el abandono de la carrera cuando los alumnos tienen bajo capital escolar.

En el segundo nivel se utiliza el tipo de carrera para agrupar a los alumnos, siendo los alumnos que eligieron una Ingeniería los que tienen más probabilidad de abandono y los que eligieron Ciencias de la Salud o Pedagogías los que tienen más probabilidad de permanencia. Este resultado también es consistente con los coeficientes de localización que construimos.

En el tercer nivel, el árbol utiliza el género de los alumnos para agruparlos, siendo en todos los casos más probable (en torno a 10 puntos porcentuales) la permanencia de las alumnas, independientemente del tipo de carrera que estén cursando. Según el modelo, los alumnos (varones) con poco capital escolar que eligieron una Ingeniería (nodo 7) son los que mayor probabilidad tienen de abandonar la carrera (79\%), frente a éstos, las alumnas con alto capital escolar que eligieron Ciencias de la Salud o Pedagogías (nodo 14) son las que tienen una menor probabilidad de abandonar sus carreras $(18,8 \%)$.

En resumen, podemos afirmar que la elección de carrera, determinada en parte por las estrategias de clase y por la división patriarcal del trabajo, resulta fundamental para explicar la competencia universitaria. A esto hay que sumar el capital escolar de los alumnos (transformación escolar de sus condiciones de existencia) y el género. 


\section{Gráfico 4: Determinantes de la competencia universitaria}

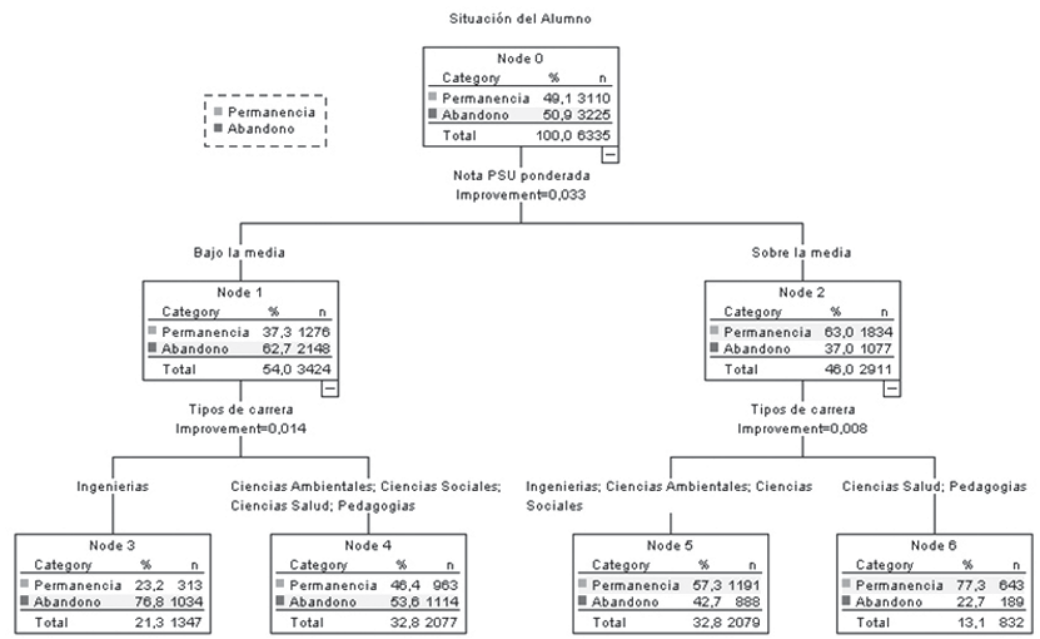

Fuente: Elaboración propia

\section{Conclusiones}

A lo largo del análisis realizado, hemos podido comprobar que efectivamente, como afirma Bourdieu, las condiciones de existencia de los alumnos determinan sus trayectorias escolares, incluso después de alcanzar la universidad.

En el tercer momento de la trayectoria escolar, hemos podido mostrar cómo la posición social (clase social y campo social), la posición espacial, el capital escolar (transformación escolar de las condiciones de existencia) y muy especialmente el género, determina la elección de carrera universitaria. Hemos verificado que las clases superiores eligen carreras de alto estatus pero no de alta dificultad, mientras que los proletarios eligen carreras de bajo estatus y baja dificultad. El campo social familiar, en general, tiene un efecto atractor hacia las carreras relacionas con él. También comprobamos que los alumnos con un elevado capital escolar eligen carreras de alto estatus, frente a los alumnos con poco capital escolar que eligen las carreras con menor valoración social. Sin embargo, como decíamos, es el género de los estudiantes la propiedad más importante para determinar la carrera que cursarán. Siguiendo una la división patriarcal del trabajo, los alumnos varones se orientan a carreras relacionadas con trabajos productivos, mientras que las alumnas se decantan por las que están más relacionadas con trabajos reproductivos. 
Posteriormente, en el cuarto momento de la trayectoria escolar, comprobamos cómo el género, el capital escolar y, sobre todo, el tipo de carrera elegida determinan la competencia universitaria. Pudimos verificar cómo el aumento del capital escolar en los alumnos disminuye la probabilidad de que abandonen la carrera. También comprobamos que la posición social de los alumnos influye en la probabilidad de permanencia (o abandono) de la carrera mediante dos efectos diferentes que interactúan de forma compleja, el grado de selección y el capital lingüístico. Parece que el efecto de selección explica mejor la permanencia de los alumnos en las carreras de mayor estatus y dificultad de entrada, y, en general, en alumnos varones, mientras que el capital lingüístico explica mejor la permanencia en las carreras difíciles (con alta probabilidad de abandono) y en las alumnas. Pero es el tipo de carrera cursada la variable más importante para explicar la probabilidad que tiene los alumnos de abandonarla. Las carreras pueden ser ordenadas por su grado de dificultad y este orden es independiente a la posición social, al capital escolar o al género de los alumnos que las cursan. Es un orden consistente y persistente que está determinado, según deducimos de Bourdieu, por la configuración histórica del campo universitario chileno y por la posición que ocupa cada carrera en dicho campo.

El género de los alumnos resultó ser la tercera propiedad más importante (por detrás del tipo de carrera y del capital escolar) para explicar el abandono universitario. En todos los tipos de carrera estudiados, las alumnas tienen más probabilidad de permanencia (unos 10 puntos porcentuales) que los alumnos varones. Esta superioridad femenina es muy consistente, se mantiene también en los distintos tipos de colegio, en los distintos niveles de capital escolar y en casi todas las posiciones sociales (con la excepción del proletariado agrario) y espaciales. El género resulta por tanto una propiedad social fundamental para explicar la competencia universitaria. Nosotros, sin embargo, no habíamos incorporado ninguna explicación teórica que anticipase este efecto, aunque este hecho es general para Chile (González, 2005) y frecuente en muchos países (Martínez, 2007).

Como señala Martínez (2007), hay que mirar fuera del propio sistema escolar para poder entender la rápida incorporación de las mujeres a la universidad y la superación en muchos países de sus pares masculinos. Tenemos que fijarnos en los grandes cambios políticos y al interior de las familias que han permitido, entre otras cosas, un aumento de la participación femenina en el mercado laboral. Ahora bien, estos cambios sociales explican el incremento de la presencia de mujeres en el universidad, pero no explican que tengan una mayor competencia escolar que los hombres durante toda la trayectoria escolar (MINEDUC, 2010). Esta diferencia podría ser explicada por la socialización de género, ya que ésta produce dos subjetividades diferentes, la masculina y la femenina (Bourdieu, 2003: 55-56), pudiendo estar la segunda mejor adaptada al tipo de trabajo que requiere el sistema escolar.

En conclusión, aunque el sistema escolar chileno tiene un importante margen de mejora, superando, por ejemplo, la fuerte segmentación social 
con la que agrupa actualmente a los alumnos a partir de su origen social ${ }^{12}$ (a las clases superiores en los colegios privados, a las medias en los subvencionados y al proletariado en los municipales), lo cierto es que la experiencia internacional no ha conseguido reducir significativamente la determinación de los resultados académicos por las diferencias sociales de los alumnos (Martínez, 2007). En este sentido, compartimos la opinión de otros autores (Caravana, 2001; Martín, 2004 y Martínez, 2007) que consideran que el sistema escolar por sí solo tiene en realidad muy poca capacidad para reducir las diferencias sociales y funciona más bien como un espejo del resto de la sociedad. El sistema escolar realiza fundamentalmente la transformación de las condiciones de existencia de los alumnos en capital cultural institucionalizado (titulación académica) y permite legitimar la desigualdad social en base a la posesión de dicho capital, que es presentado como un logro individual (Bourdieu, 2001). Por tanto, la política pública necesaria para reducir la brecha educativa entre clases sociales pasa principalmente por una política económica redistributiva que reduzca sustancialmente la desigualdad social ${ }^{13}$ y aporte los recursos necesarios para que el Estado pueda financiar una educación pública ${ }^{14}$ de suficiente calidad como para atraer a las clase medias e incluso a una parte de las clases superiores.

\section{Propuestas de investigación}

Nuestras propuestas para próximos trabajos se dirigen en dos direcciones, en primer lugar, hay que profundizar en la comprensión de los determinantes sociales de la trayectoria escolar, especialmente en los determinantes de la elección de carrera, por su gran importancia tanto en la permanencia de los alumnos en la universidad como en la trayectoria social de los egresados. También se debe profundizar el estudio de la compleja relación existente entre el capital lingüístico y el grado de selección como determinantes de la competencia universitaria para cada tipo de carrera y género. Nuestros resultados sugieren que esta relación es diferente, no sólo entre carreras (cómo esperábamos) sino también entre hombres y mujeres. Finalmente, en el marco del estudio de la trayectoria escolar, habría que entender mejor la relación entre la socialización de género, las condiciones de existencia para cada género (política, familiar y laboral) y el trabajo escolar.

En segundo lugar, habría que extender el análisis bourdieuniano desde la trayectoria escolar a la trayectoria sociolaboral de los egresados. Nuestra hipótesis para ese momento, es que en el mercado laboral se reactivarán con fuerza los efectos de las condiciones de existencia de los egresados, en especial el género, el capital social y lingüístico de sus familias y el conocimiento de éstas de su campo social, generando lo anterior trayectorias sociolaborales diferentes para egresados con el mismo capital cultural institucionalizado (título universitario). Trabajos exploratorios (ORDHUM, 2011) sugieren que el proyecto de vida de los egresados chilenos está determinado por su género y que las estrategias para llevar a cabo dichos proyectos están determinadas por la clase social. 


\section{Notas}

${ }^{1}$ Ley, costumbre y valores dominantes, que en una sociedad determinada y en momento histórico determinado, regulan la transmisión intergeneracional del capital.

2 En términos relativos, no absolutos. La inversión escolar de las clases superiores es mayor, pero las clases medias hacen un mayor esfuerzo y asumen más riesgos teniendo en cuenta su volumen de capital.

${ }^{3}$ Para un análisis bourdieuniano del patriarcado, ver La dominación masculina (2003).

${ }^{4}$ Relaciones de poder entre géneros.

${ }^{5}$ En este artículo, por un problema de espacio, sólo se mostrarán los resultados de los dos últimos momentos del modelo, esto es, de la elección del tipo de carrera y de la competencia universitaria.

${ }^{6}$ También se realizaron análisis discriminantes para completar los resultados. No serán expuestos para ganar espacio.

${ }^{7}$ Además del área del estudio, para la agrupación de carreas de utilizaron los criterios de estructura de género y grado de dificultad. Los cinco grupos generados son relativamente homogéneos y mantienen diferencias estadísticas significativas entre sí.

${ }^{8}$ En España, por ejemplo, se ha demostrado que las diferencias aparentes de capital escolar que presentan los alumnos de distintos tipos de colegios (privados, subvencionados y públicos) desaparecen cuando se utiliza como variable de control la clase social, concretamente el capital escolar de los padres. Es decir, en el caso español el tipo de colegio no determina el capital escolar de los alumnos. Ver Informe de la Inclusión Social en España 2009.

${ }^{9}$ Recordamos aquí que por "calidad escolar" entendemos la suma de los efectos de relación con los docentes (determinadas por el capital cultural y las expectativas de estos) más los efectos de relación con los compañeros (composición de clase del colegio).

${ }^{10}$ Hemos ordenado los distintos tipos de carreras a partir de los resultados obtenidos en el análisis estadístico de nuestra muestra como la única aproximación posible a las expectativas. Somos conscientes, sin embargo, del riesgo que supone inferir lo subjetivo (representaciones sociales) a partir de lo objetivo (hechos sociales).

a. El ordenamiento basado en estatus lo hemos realizado a partir de la participación de las clases superiores en cada tipo de carrera: $1^{\circ}$ Ciencias de la Salud, $2^{\circ}$ Ciencias Sociales, $3^{\circ}$ Ingenierías, $4^{\circ}$ Ciencias Ambientales y $5^{\circ}$ Pedagogías.

b. El ordenamiento basado en la exigencia de entrada lo hemos realizado a partir del promedio de notas de la PSU de los alumnos de cada carrera: $1^{\circ}$ Ciencias de la Salud, $2^{\circ}$ Ciencias Sociales, $3^{\circ}$ Ingenierías, $4^{\circ}$ Pedagogías y $5^{\circ}$ Ciencias Ambientales.

c. Y el ordenamiento basado en el grado de dificultad lo hemos realizado a partir del coeficiente de localización de la permanencia en cada tipo de carrera: $1^{\circ}$ Ingenierías, $2^{\circ}$ Ciencias ambientales, $3^{\circ}$ Ciencias Sociales, $4^{\circ}$ Pedagogías y $5^{\circ}$ Ciencias de la Salud. 
Polis, Revista Latinoamericana, Volumen 14, $N^{\circ}$ 42, 2015

${ }^{11}$ Utilizando como indicador el abandono universitario. Los resultados son similares cuando utilizamos el promedio de notas conseguido en la carrera.

${ }^{12}$ Los alumnos de clase proletaria que cursan la educación media en colegios privados, es decir, que sociabilizan mayoritariamente con los alumnos de clases superiores (con mayor capital lingüístico), obtienen mejores resaltados académicos que los alumnos proletarios que se sociabilizan mayoritariamente con otros proletarios (situación de los colegios municipales). La concentración espacial (en los colegios) de los alumnos con las mismas propiedades sociales supone la perfecta conservación de sus diferencias de origen, al negarles la posibilidad de cualquier sociabilidad entre clases (ORDHUM, 2012).

${ }^{13}$ La distribución del ingreso en Chile está entre las peores del mundo con un Índice Gini de 0,53 (CASEN 2009).

${ }^{14}$ En Chile, el gasto público en educación supone sólo el 4\% del PIB estando por debajo del promedio latinoamericano que se sitúa en el 5,3\% del PIB (CEPAL, 2008). 


\section{Bibliografía}

Apple, M. W. y Beane, J. A. (comps.) (1997), Escuelas democráticas, Morata, Madrid.

Beltrán, J. (2014), La escuela y sus metáforas, Tirant lo Blanch, Valencia.

Bernstein, B. (1990), Poder, educación y conciencia. Sociología de la transmisión cultural, El Roure, Barcelona.

Boudon, R. (1983), La desigualdad de oportunidades, Laia, Barcelona.

Bourdieu, P. (2001), Poder, Derecho y Clases Sociales, Desclée, Bilbao.

Ídem (2003), La dominación masculina, Anagrama, Barcelona.

Ídem (2006), La distinción. Criterio y bases sociales del gusto, Taurus, Madrid.

Ídem (2008), Homo academicus, Siglo XXI, Madrid.

Bourdieu, P. y Passeron, J. C. (2001), La reproducción. Elementos para una teoría del sistema de enseñanza, Popular, Madrid.

Breen, R. y Goldthorpe, J. H. (2000), “Explaining Educational Differentials”, en J. H. Goldthorpe (dir.), On Sociology, Oxford University Press, Oxford.

Brunner, J. J. (2009A), Educación superior en Chile, Instituciones, mercados y políticas gubernamentales 1967- 2007, Ed. Universidad Diego Portales, Santiago de Chile.

Ídem (2009B), “Apuntes sobre sociología de la educación superior en contexto internacional, regional y local”, Estudios Pedagógicos, vol. 35(2), pp. 203-230, Valdivia.

Brunner, J. J. y Uribe, D. (2006), Mercados Universitarios, El nuevo escenario de la educación superior en Chile, Ed. Universidad Diego Portales, Santiago de Chile.

Castillo, J. (2007), “Demandas juveniles a la educación, la necesidad de fortalecer las trayectorias educativas en el sistema escolar”, Revista Observatorio de Juventud, $\mathrm{n}^{\circ} 16$, Santiago de Chile.

Castillo, J. y Cabezas, G. (2010), “Caracterización de Jóvenes primera generación en Educación Superior. Nuevas Trayectoria hacia la equidad educativa”. Revista Calidad en la Educación, No 32, Santiago de Chile.

Donoso, S. y Schiefelbein, E. (2007), “Modelos de Retención de Estudiantes en la Universidad. Visión desde la exclusión social”. Estudios Pedagógi- 
cos, vol. 23(1), pp. 7 -27, Valdivia.

Escobar, M. (2007), El análisis de segmentación, técnicas y aplicaciones de los árboles de clasificación, CIS, Madrid.

Franco, R., León A. y Atria, R. (2007), Estratificación y Movilidad Social en América Latina. Transformaciones estructurales de un cuarto de siglo, LOM Ediciones, Santiago de Chile.

Giroux, H. (2001), Cultura, política y práctica educativa, Graó, Barcelona.

González, L. E. (2005), Estudio sobre la repitencia y deserción en la educación superior chilena, Ed. Digital Observatory For Higher Education in Latin America and The Caribbean, IESALC-UNESCO, Santiago de Chile.

Isard, W. (1971), Métodos de análisis regional, Ariel, Barcelona.

Martín, E. (2004), “De la reproducción al campo escolar” en Pierre Bourdieu, las herramientas del sociólogo, Editorial Fundamentos, Madrid.

Martínez, J. S. (2007), “Clase social, género y desigualdad de oportunidades educativas”, Revista de Educación, n 342, pp. 287-306, Madrid.

Meller, P. (2010), Carreras Universitarias. Rentabilidad, selectividad y discriminación, Centro de Investigación Avanzada en Educación, Universidad de Chile, Uqbar Editores, Santiago de Chile.

MINEDUC (2010), Indicadores de la educación en Chile 2007-2008, Santiago de Chile.

Ídem, Índices 2011, Consejo Nacional de Educación, extraído 01/10/2011 de http,//www.cned.cl/public/Secciones/SeccionIndicesEstadisticas/ indices_estadisticas.aspx

OCDE (2009), La Educación Superior en Chile, Serie Revisión de Políticas Nacionales de Educación, OCDE - Banco Mundial, Santiago de Chile.

Ídem (2010), Estudio económico de Chile 2010, Ed. Síntesis, extraído 11/ 06/2012 de http,//www.oecd.org/dataoecd/7/38/44493040.pdf

ORDHUM (2011), Discursos sobre la región de Antofagasta en el contexto de la migración regional, Universidad Católica del Norte, Ediciones Universitarias, Antofagasta.

ORDHUM y CIGTE (2013), Determinantes sociales de la trayectoria escolar de los universitarios chilenos, Universidad Católica del Norte, Ediciones Universitarias, Antofagasta. 
RIDAI (2010), Indicadores RIDAI (2005-2009), Proyecto MECESUP UCN0607 Desarrollo y Fortalecimiento de la Capacidad y la Cultura de Análisis Institucional de una Red Universitaria, Documento no publicado.

Willis, P. (1988), Aprendiendo a trabajar, Akal, Madrid.

Zapata, G. y Tejeda, I. (2008), Aseguramiento de la Calidad, Políticas Públicas y Gestión Universitaria. Informe Final Proyecto ALFA, nº. DCIALA 2008/42, pp. 1- 64.

Recibido: 12.03.2014

Aceptado: 18.03.2015 